DOI 10. 18307/2019. 0513

(C) 2019 by Journal of Lake Sciences

\title{
不同时间尺度青海湖沉积物总有机碳对气候变化的敏感性
}

\author{
张 姚 ${ }^{1}$, 吴 铎 ${ }^{1 * *}$, 张 欢 $^{1}$, 周爱锋 ${ }^{1}$, 王苏民 ${ }^{2}$, 陈发虎 ${ }^{1,3}$ \\ ( 1 : 兰州大学资源环境学院,西部环境教育部重点实验室,兰州 730000) \\ (2:中国科学院南京地理与湖泊研究所,南京 210008) \\ (3: 中国科学院青藏高原研究所,高寒生态重点实验室,北京 100101)
}

\begin{abstract}
摘 要: 湖泊沉积物总有机碳 (TOC) 含量通常作为表征流域和湖泊生产力的指标, 在亚洲季风区也常常被当作夏季风的 代用指标, 被广泛应用于气候与环境变化研究. 本文梳理了过去千年、全新世以及冰期一间冰期时间尺度上青海湖沉积物 TOC 的变化特征, 并探讨了其指示气候变化的敏感性与有效性. 结果表明, 过去千年青海湖沉积物 TOC 含量与区域暖季 温度和降水表现出较为一致的周期性波动. 通过对比全新世区域夏季温度、基于孢粉的降水定量重建结果, 以及湖泊水 位、风沙活动反映的湿度状况等, 发现不能简单地将青海湖沉积物 TOC 含量或沉积通量作为夏季风强度或者季风降水强 度的代用指标. 青海湖沉积物 TOC 含量在冰期和间冰期表现出巨大的差异,指示了冰期一间冰期时间尺度上较大的温度 与降水变幅. 因此, 不同地域条件及不同时间尺度下, 湖泊沉积物 TOC 对气候变化的敏感性不同, 将湖泊沉积物 TOC 含 量作为亚洲夏季风的代用指标需要特别谨慎,特别是在高寒气候区.
\end{abstract}

关键词: 青海湖;总有机碳;有机质;敏感性;夏季风强度

\section{Total organic carbon sensitivity to climate change from Lake Qinghai sediments at different time scales}

\author{
ZHANG Yao ${ }^{1}$, WU Duo ${ }^{1 * *}$, ZHANG Huan $^{1}$, ZHOU Aifeng $^{1}$, WANG Sumin ${ }^{2}$ \& CHEN Fahu ${ }^{1,3}$ \\ (1: MOE Key Laboratory of Western China's Environmental Systems, College of Earth and Environmental Sciences, Lanzhou \\ University, Lanzhou 730000, P.R. China) \\ (2: Nanjing Institute of Geography and Limnology, Chinese Academy of Sciences, Nanjing 210008, P.R. China) \\ (3: Key Laboratory of Alpine Ecology, Institute of Tibetan Plateau Research, Chinese Academy of Sciences, Beijing 100101, \\ P.R.China)
}

\begin{abstract}
Total organic carbon ( TOC) content of lacustrine sediments has been widely used in the climatic and environmental studies as a proxy of productivity in the catchment and lake water; it is also used as an index of monsoon precipitation in the regions dominated by the Asian summer monsoon. In the present paper, we summarized the variation characteristics of TOC in Lake Qinghai sediments at scales of past millennium, the Holocene and the glacial-interglacial; and discussed the sensitivity and applicability of TOC for indicating climate change. The results indicate that the variation of TOC in Lake Qinghai sediments during the past millennium is consistent with that of regional warm season temperature, as well as the precipitation. After compared with regional summer temperature, pollen-based precipitation reconstruction results, and moisture evolution inferred from water level of lakes and aeolian activity history, we found that TOC content or flux cannot be regarded as a reliable index of the intensity of summer monsoon or monsoonal precipitation during the Holocene. TOC content from Lake Qinghai during the Holocene and the last glacial were distinctly different, indicating huge difference of precipitation and temperature at the glacial-interglacial scale. Therefore, the sensitivity of TOC in lake sediments to climate change is different at different places or different time scales; it should be very careful to use lacustrine TOC as an index of Asian summer monsoon intensity, especially in the cold and high-altitude regions.
\end{abstract}

* 中国博士后科学基金特别资助项目(2019T120962)、中央高校基本科研费专项基金项目 ( lzujbky-2017-211, lzujbky2019-kb01) 和中国科学院国际合作局对外合作重点项目 (131C11KYSB20160061) 联合资助. 2018-12-12 收稿; 2019-04-01 收修改稿. 张姚(1994 ), 女, 硕士研究生;E-mail: zhangyao17@ lzu.edu.cn.

** 通信作者;E-mail: dwu@ lzu.edu.cn. 
Keywords: Lake Qinghai; total organic carbon; organic matter; sensitivity; summer monsoon intensity

有机质作为湖泊沉积物的重要组成部分, 其含量通常反映了流域有机质输人与湖泊生产力的变化. 尽 管受到外源、内源以及沉积后降解等因素的影响, 湖泊沉积物有机质或者总有机碳 (TOC) 含量是重建湖泊 生产力和气候变化特征的重要代用指标,仍被广泛应用于古气候研究中. 一般认为在暖湿气候时期,湖泊内 水生生物及藻类发育, 并且流域内植被茂盛, 因此沉积物中有机质含量较高. 对于地处寒冷气候区的湖泊而 言, 气温可能是影响生物生长的主导因素, TOC 含量在一定程度上可以反映温度的变化 ${ }^{[1-2]}$. 此外, 在季风区 乃至青藏高原高寒区的湖泊沉积研究中,TOC 含量也常常被当作亚洲夏季风或者夏季风降水强度的可靠代 用指标 ${ }^{[3-8]}$. 然而, 不同的湖泊陆源和自生有机质的贡献比例大不相同,且不同自然条件下, 流域和湖泊生物 量或生产力变化的限制因子也不一样,所以对 TOC 变化的解释不能一概而论.

青海湖位于青藏高原东北缘,地处东亚季风边缘区,同时也受西风环流的影响,对亚洲气候变化响应敏 感, 而且这一区域也是史前人类定居青藏高原的重要区域 ${ }^{[9-10]}$. 过去几十年科学家对青海湖开展了系统的研 究, 重建了该区域晚更新世以来的环境变化与亚洲季风演化历史 ${ }^{[4,11]}$, 并对这一区域史前人类与环境相互作 用开展了深人研究 ${ }^{[9-10,12-14]}$. 但由于代用指标环境指示意义的差异, 不同指标重建的气候变化结果往往存在 相互抵牾之处 ${ }^{[15]}$. 譬如, 就全新世而言, $\mathrm{An}$ 等 ${ }^{[4]}$ 利用青海湖沉积物 $\mathrm{CaCO}_{3}$ 和 $\mathrm{TOC}$ 沉积通量建立了亚洲夏季 风指数, 随后诸多研究将青海湖 TOC 作为夏季风降水强度的代用指标而加以运用 ${ }^{[5-8]}$, 并一致认为早全新世 夏季风强盛、降水较多. 基于青海湖沉积物中介形虫壳体的氧同位素 ${ }^{[4,16]}$ 、叶蜡氢同位素 ${ }^{[17]}$ 以及元素地球化 学指标 ${ }^{[18]}$ 等的夏季风重建结果进一步支持了这种观点. 但这样的结论与早全新世青藏高原东北缘较低的 湖泊水位状态 ${ }^{[19-23]}$ 以及区域广泛发育的风沙活动事实 ${ }^{[24-27]}$ 相矛盾. 同时该区湖泊沉积物狍粉资料却反映中 全新世森林最为发育 ${ }^{[11,28-29]}$; 基于狍粉的降水定量重建结果也显示中全新世降水最多 ${ }^{[30-31]}$; 作为河流径流 输人的红度指标也揭示出中全新世降水最多 ${ }^{[32]}$. 在百年尺度乃至冰期一间冰期尺度上, 青海湖 TOC 的变化 与其他季风指标也不乏相悖之处. 因此, 非常有必要对湖泊沉积物 TOC 能否或者在何种时间尺度上作为亚 洲夏季风指标开展讨论. 本文通过梳理青海湖沉积物过去千年、全新世以及冰期一间冰期时间尺度上的 TOC 变化特征, 探讨其在不同时间尺度上对气候环境变化指示的敏感性与有效性,并辨识其是否可以作为亚洲 季风降水变化的有效指标.

\section{1 青海湖及环境变化研究概况}

青海湖位于青藏高原东北缘, 是中国最大的咸水湖 (盐度 $14.2 \mathrm{~g} / \mathrm{L}, \mathrm{pH}$ 为 9.1 ), 湖泊面积 $4260 \mathrm{~km}^{2}$, 流 域面积 $29660 \mathrm{~km}^{2[8]}$. 湖面高程 $3194 \mathrm{~m}$, 湖泊平均水深 $21 \mathrm{~m}$, 最大水深约 $27 \mathrm{~m}^{[6]}$ (图 $1 \mathrm{~b}$ ). 湖区处于亚洲夏季 风和西风共同影响区域; 季节性温度差异较大, 年平均气温约为 $-0.7^{\circ} \mathrm{C}^{[6]}$; 年平均降水量可达 $370 \mathrm{~mm}$, 且季 节分配不均,夏季降水占全年降水的 $65 \%$ 左右 ${ }^{[4]}$. 现代水汽示踪表明青海湖流域的水汽主要来自于东南部 水汽、南部水汽以及西北部水汽 ${ }^{[17]}$ (图 1a), 其中以东南部水汽为主导 (图 1c). 古气候研究表明该区域降水 主要受到东亚季风的控制 ${ }^{[11,33-34]}$.

青海湖一直是国际国内环境变化研究的焦点. 从 20 世纪初开始的湖区湖泊水文地质调查, 再到 20 世 纪中叶以来尤其是 1980s 之后基于钻孔的环境变化研究,特别是国际大陆科学钻探计划实施以来,已在青海 湖获取了诸多钻孔, 开展了系统的环境变化研究. 长时间序列钻孔包括 $\mathrm{QH} 85-14 \mathrm{~A} / \mathrm{B} / \mathrm{C}^{[28,35]} 、 \mathrm{QH} 1^{[36]} 、 \mathrm{QH}-$ $200{ }^{[11]} 、 \mathrm{QH}-2005^{[37]} 、 \mathrm{LQDP} 05-1 \mathrm{~F}^{[4]} 、 \mathrm{QH} 07^{[6]} 、 \mathrm{QH}-2011^{[22]}$ 和 $2 \mathrm{C}^{[38]}$ 等. 同时也获取了一系列过去千年尺度的 短钻孔, 比如 $Q I N G-1 / 3 / 6 / 10^{[39-40]} 、 \mathrm{QHN} 3 / 01^{[33]} 、 \mathrm{QH} 0407-\mathrm{C}-1 / 2^{[34,41-42]}$ 和 $\mathrm{QH} 00 \mathrm{~A}^{[1-2]}$ (图 1b). 基于这些钻孔， 大量关于不同时间尺度环境变化的研究成果相继发表 ${ }^{[1-2,4-8,11,15-18,21-23,32-42]}$.

\section{2 青海湖沉积物不同时间尺度 TOC 变化}

\section{1 过去千年青海湖沉积物有机质和 TOC 变化及其控制因素}

大量研究表明, 湖泊沉积物在 $550^{\circ} \mathrm{C}$ 条件下的质量损失量可以衡量有机质的含量 ${ }^{[43-44]}$. 从青海湖 6 个钻 孔的有机质和 TOC 随深度变化的结果 (图 2a f) 可以看出, 这些钻孔的有机质和 TOC 表现出相似的周期性 

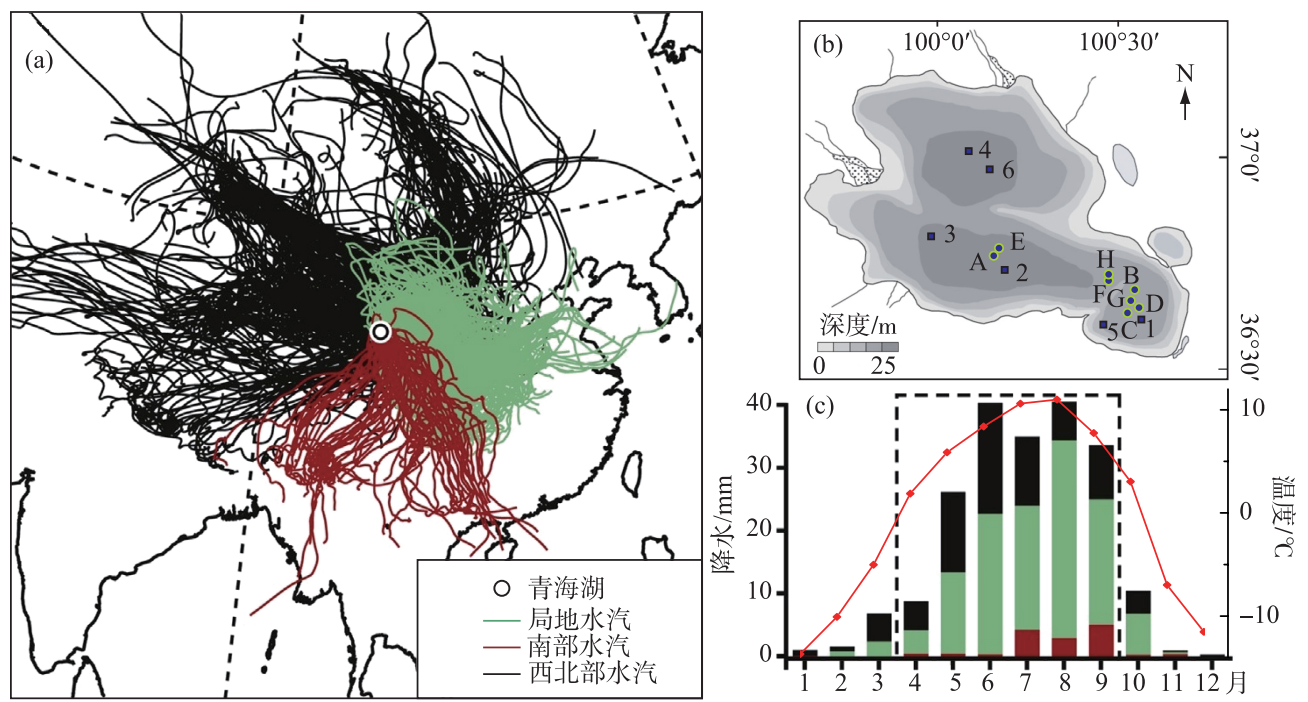

图 1 研究区现代气候状况及青海湖钻孔位置示意图

(a:青海湖流域现代水汽来源示意图 (修改自文献[17],白底黑色圆圈代表青海湖)； $\mathrm{b}$ : 青海湖水深及钻孔位置分布图 (底图引自文献 [6], 图中 $\mathrm{A}$ 为 QH85-14B; B 为 QH85-16A; $\mathrm{C}$ 为 $\mathrm{QH}-2000 ; \mathrm{D}$ 为 $\mathrm{QH}-2005 ; \mathrm{E}$ 为 $\mathrm{LQDP05}-1 \mathrm{~F} ; \mathrm{F}$ 为 $\mathrm{QH} 07 ; \mathrm{G}$ 为 $\mathrm{QH}-2011 ; \mathrm{H}$ 为 $2 \mathrm{C} ; 1$ 为 QING-3; 2 为 QING-5; 3 为 QING-7/8; 4 为 QING-11; 5 为 QH00A; 6 为 QH0407-C-1/2); $\mathrm{c}$ : 青海湖逐月平均 温度 $\left(1976-2007\right.$ 年) ${ }^{[4]}$ 、降水以及不同来源水汽所占比例 ${ }^{[6]}$ 示意图 (修改自文献 [17] ) )

Fig.1 Modern climate of the study area and locations of sedimentary cores from Lake Qinghai

(a. Modern precipitation sources for the Lake Qinghai catchment (a is modified from reference [17];

Black circle with white background in a represents Lake Qinghai); b. Isobath of Lake Qinghai and locations of drilled cores (b is modified from reference [6]; A: QH85-14B; B: QH85-16A; C: QH-2000; D: QH-2005;

E: LQDP05-1F; F: QH07; G: QH-2011; H: 2C; 1: QING-3; 2: QING-5; 3: QING-7/8; 4: QING-11;

5: QH00A; 6: QH0407-C-1/2) ; c. Amount of monthly temperature (1976-2007) ${ }^{[4]}$ and precipitation ${ }^{[6]}$ that falls at Lake Qinghai as a result of the three trajectories shown in a (c is modified from reference [17]))

变化特征, 这不仅表明有机质含量波动可以代表 TOC 含量变化, 也说明青海湖湖盆的不同水深区岩芯具有 很好的对比性. 沈吉等 ${ }^{[1]}$ 和张恩楼等 ${ }^{[2]}$ 对钻孔 QHOOA 的研究显示, 过去千年青海湖沉积物 TOC 存在数次周 期性波动 (图 2f), 揭示出青海湖区域冷湿一暖干交替的气候组合类型, TOC 的高值对应暖期, 低值对应冷 期; 通常在暖湿气候时期, 湖泊内水生生物及藻类发育, 并且流域内植被茂盛, 因此沉积物中含有较高的有 机质. 对于地处寒冷气候区的青海湖而言, 气温可能是影响生物量的主要因素, 因此 TOC 在一定程度上反映 了温度的变化 ${ }^{[2]}$.

近 30 年来, 随着青藏高原持续变暖, 遥感观测显示高原生长季植被活动呈持续增强趋势 ${ }^{[45]}$. 就青海湖 流域而言, 陈晓光等 ${ }^{[46]}$ 使用 $1981-2003$ 年月归一化植被指数, 计算了青海湖地区植被覆盖度, 发现 22 年以 来增加了 $14 \%$. 青海湖周边的天峻、刚察、共和以及茶卡 4 个气象站 1958-1998 年的气象资料表明, 青海湖 地区降水年际变化较大,但无明显的长期趋势, 而该地区的年平均气温却明显升高 ${ }^{[47]}$. 这说明在全球变暖 的背景下, 青海湖流域陆地植被生产力提高. 伴随着全球变暖和流域人类活动的加剧, 青海湖水体营养水平 也相应提高. 2012 年的水质情况相较于 $1960 \mathrm{~s}$ 表现为水体 $\mathrm{NH}_{4}^{+} 、 \mathrm{NO}_{3}^{-}$、总磷、总氮浓度的升高 ${ }^{[48]}$, 这些营养物 质的供应势必增强湖泊的生产力, 同时水体增大的化学需氧量和降低的透明度也间接说明了这点. 另外, $\mathrm{C} / \mathrm{N}$ 比值表明最近几十年的沉积物中有机质主要来源于湖泊自生植物 ${ }^{[48]}$. 不同短钻揭示的青海湖沉积物 TOC 变化具有较好的可对比性 (图 2), 其近几十年以来均表现出增加趋势 ${ }^{[1-2,34,39-40]}$, 这恰恰说明了温度增高 
导致的陆源和水生有机质供给量增加. 因此,温度的升高可能是导致过去几十年青海湖沉积物有机质含量 增加的主导因素.

张家武 ${ }^{[39]}$ 的研究结果显示, 青海湖沉积物过去千年有机质含量与 $\mathrm{CaCO}_{3}$ 的周期性变化呈显著负相关. $\mathrm{An}$ 等 ${ }^{[4]}$ 认为青海湖 $\mathrm{CaCO}_{3}$ 的沉积主要受控于水体中的 $\mathrm{Ca}^{2+}$ 含量, 而水体中的 $\mathrm{Ca}^{2+}$ 主要受到河流输人量的影 响, 所以沉积物中 $\mathrm{CaCO}_{3}$ 的含量可以反映区域降水的变化; 同时诸多研究也将青海湖 TOC 作为季风降水指 标加以应用 ${ }^{[4-8]}$, 认为高 TOC 含量反映强降水. 由此可见这种解释至少在过去千年内的百年时间尺度上二者 是相互矛盾的. 如果认为过去千年里 $\mathrm{CaCO}_{3}$ 含量在百年时间尺度上的波动可以反映降水的变化, 那么与之 呈相反变化趋势的 TOC 势必受到非降水因素的制约.

通过对比基于树轮等重建的青藏高原过去 2000 年的暖季温度记录 ${ }^{[49]}$ ( 图 $2 \mathrm{~g}$ ), 同时结合青藏高原北部 库赛湖的纹层厚度重建的过去 1600 年夏季温度变化 ${ }^{[50]}$, 可以发现周期性的温度波动可能是高原, 特别是高 原北部的共同特性 ${ }^{[7,50-52]}$, 而且这种周期性的温度波动与青海湖有机质或 TOC 含量的变化具有相似性. 此 外, 对比青藏高原东北部的降水记录 ${ }^{[53]}$, 以及能够反映区域干湿变化的西宁洪涝指数 ${ }^{[34]}$ 可以发现, 降水除 了与温度表现出相似的变化趋势之外, 更存在强烈的年代际波动. 考虑到青海湖顶部沉积物过去近千年有 限的埋藏后还原成岩作用, 其 TOC 含量主要受到有机质来源总量的控制, 进而反映了降水与温度共同影响 下流域和湖泊生产力的变化.

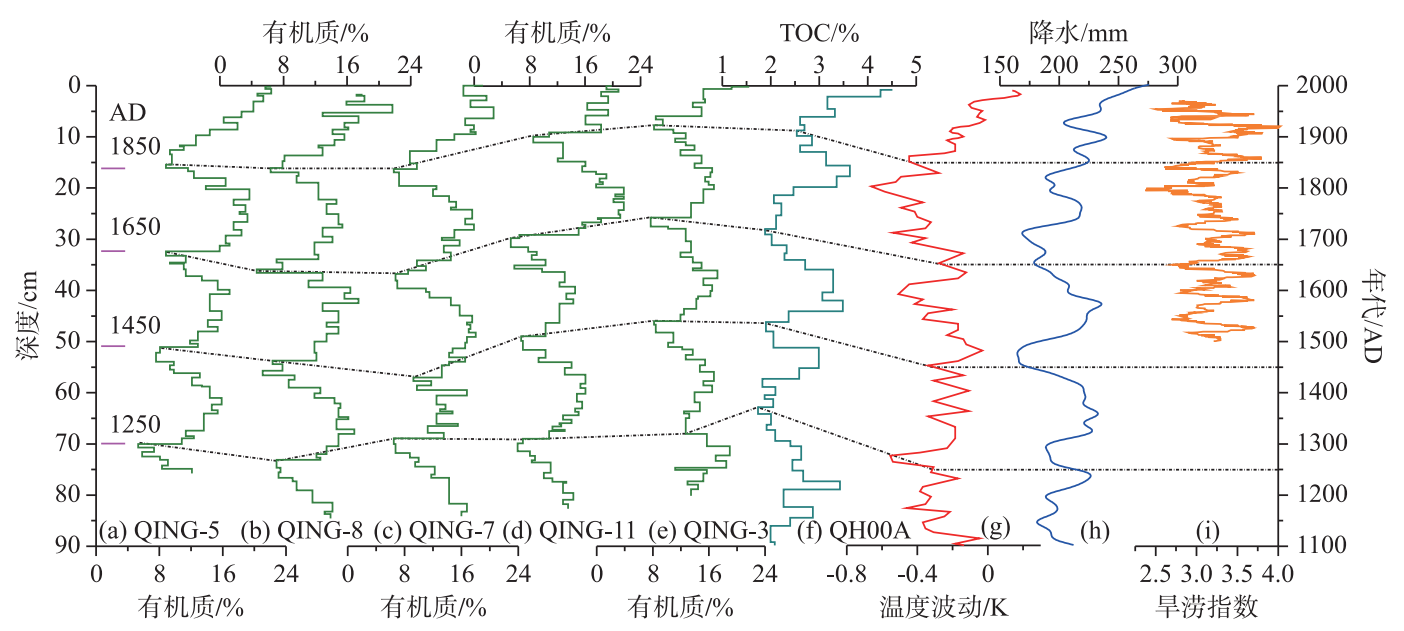

图 2 过去千年青海湖沉积物有机质和 TOC 含量变化与区域温度降水对比 $\left(\mathrm{a} \sim \mathrm{e}\right.$ : 有机质含量 ${ }^{[40]} ; \mathrm{f}$ : TOC 含量 ${ }^{[1]}$; $\mathrm{g}$ : 青藏高原温度波动 ${ }^{[49]}$;

$\mathrm{h}$ : 树轮重建的青藏高原东北部降水 ${ }^{[53]} ; \mathrm{i}$ : 西宁旱涝指数 ${ }^{[34]} ; \mathrm{a} \sim \mathrm{f}:$ 深度; $\mathrm{g} \sim \mathrm{i}$ : 年代)

Fig.2 Variation of organic matter and TOC contents during the past millennium recorded in

Lake Qinghai and its relationship with regional temperature and precipitation (a-e: organic matter content ${ }^{[40]} ; \mathrm{f}$ : TOC content ${ }^{[1]} ; \mathrm{g}$ : Reconstructed area-weighted temperature anomalies on the Tibetan Plateau ${ }^{[49]} ; \mathrm{h}$ : Reconstructed precipitation in the northeastern Tibetan Plateau from tree rings ${ }^{[53]}$; i: Drought/Flood (D/F) index of Xining ${ }^{[34]}$; a-f: depth; g-i: age)

\section{2 全新世青海湖 TOC 变化及其与季风降水指标的冲突}

全新世青海湖数个钻孔的 TOC 相较于末次冰期均表现出显著的高值, 尤其明显的是从晚冰期到全新世 表现为突变 (图 3a e ). 基于 $\mathrm{TOC}$ 和 $\mathrm{CaCO}_{3}$ 的突变特征, $\mathrm{Liu}^{\text {等 }}{ }^{[5]}$ 提出了青海湖地区存在气候國值的概念, 并指出可能的地理屏障使得冰期环境季风减弱,进人全新世后季风突然加强. 全新世青海湖沉积物 TOC 在 早中全新世表现为高值, 并在早全新世表现出较大的波动; 而晚全新世除了钻孔 QH07 稍高之外, 其余钻孔 均表现为低值. 由于钻孔间年代模式的差异, 各钻孔 TOC 的峰值出现时间有所不同. 基于 TOC 沉积通量和 $\mathrm{CaCO}_{3}$ 含量的变化, $\mathrm{An}$ 等 ${ }^{[4]}$ 重建了夏季风指数, 并结合沉积物介形虫壳体氧同位素的变化,认为早全新世夏 
季风强盛, 中晚全新世季风衰退. 因此, 青海湖 TOC 被认为是夏季风变化或者季风降水变化的指标. 随后的 一些研究均引述这一观点, 在早全新世强季风和强降水的前提下探讨了生态环境响应等问题. 比如 Yang 等 ${ }^{[8]}$ 研究了青海湖沉积物氨氧化古菌基因丰度并讨论了其生态意义. 在一定程度上, TOC 反演的早全新世 夏季风强盛的结论似乎得到了青海湖介形虫壳体氧同位素值 $\left(\delta^{18} O\right)$ 和叶蜡氢同位素值等的佐证 ${ }^{[4,16-17]}$. 但 壳体的 $\delta^{18} \mathrm{O}$ 反映了其形成时水体的氧同位素变化, 同时也受到温度的影响 ${ }^{[54]}$, 也有研究提出受到 “水量效 应” 的控制 ${ }^{[55]}$. 对于封闭湖泊青海湖而言, 其水体氧同位素反映了流域蒸发与降水的比率 ${ }^{[35]}$; 在东亚夏季风 区, 将碳酸盐偏负的氧同位素解释为增强的夏季风强度或者季风降水越来越受到质疑 ${ }^{[56-57]}$, 事实上青海湖 沉积物氢氧同位素更可能反映了降水氧同位素的变化 ${ }^{[17,33]}$, 将其作为东亚夏季风指标实质上与石笋氧同位 素面临着同样的困境 ${ }^{[57]}$.

对青藏高原东北缘树木年轮的研究显示, 降水是树木生长的主要限制因子 ${ }^{[33,58]}$. 青海湖 QH-2000 钻孔 的狍粉组合资料显示, 木本花粉在末次冰期浓度波动较大, 全新世开始木本花粉浓度增大, 至中全新世木本 花粉浓度和含量均达到最高, 晚全新世以来降低 ${ }^{[11]}$; 与青海湖仅一山之隔的达连海沉积物木本花粉含量也 表现出相似的变化趋势 ${ }^{[29]}$. 基于青海湖狍粉资料的降水定量重建结果也显示中全新世降水最高 ${ }^{[30]}$ (图 $3 \mathrm{~g}$ ). 另外, 青海湖沉积物的红度反映了沉积物中赤铁矿的含量, 进而指示了流域河流输人量的变化, 从而可以指 示降水 ${ }^{[32]}$. QH-2000 和 QH-2005 钻孔的红度指标均表现出中全新世的高值, 指示中全新世降水最多 ${ }^{[32,37]}$. 湖泊水位波动是气候变化的结果. $\mathrm{Yu}^{[59]}$ 基于青海湖沉积物沉积相和水生植物分布绘制出青海湖全新世以 来的水位变化模式,这与 Lister 等 ${ }^{[35]}$ 的重建结果极为相似; Liu 等 ${ }^{[21]}$ 的研究表明青海湖现代沉积物有机质碳 同位素变化受到水深的影响,并基于此重建了青海湖全新世水位变化历史; Wang 等 ${ }^{[22]}$ 认为青海湖沉积物生 物标志化合物 Thaum 古菌浓度也可以反映水深变化; Liu 等 ${ }^{[23]}$ 对青海湖高湖岸沉积相辨识划分之后开展了 系统的 OSL 年代学研究, 揭示了高湖岸形成的年代. 以上这些水位重建结果和高湖岸年代学研究均显示出 早全新世没有高水位, 青海湖最高水位主要出现在中全新世. 虽然湖泊水位变化是降水与蒸发平衡的结果, 但若认为早全新世青海湖较低的湖泊水位是由强烈蒸发所致,这样的归因仍与早全新世偏负的介形虫氧同 位素相矛盾. 另外, 对青藏高原东北缘共和盆地、青海湖周边以及柴达木盆地东部的风沙剖面的研究显示, 早全新世该区风沙活动强烈 ${ }^{[25-27,60]}$, 这除了与植被的发育、沙源的充足供应有关之外, 很可能指示了相对干 旱的区域环境. 以上诸多研究表明青海湖流域乃至青藏高原东北缘早全新世相对干旱, 降水较少, 而最强降 水出现在中全新世.

现代水汽示踪表明, 南部来的水汽仅占青海湖流域植物生长季降水的 $16 \%$, 而绝大多数降水来自青海 湖东部的局地水汽 ${ }^{[17]}$, 这一区域包括了整个黄土高原以及毗邻区域, 其降水主要受到东亚季风的控制 ${ }^{[61-62]}$. $\mathrm{Xu}$ 等 ${ }^{[34]}$ 基于青海湖有机碳同位素、 $\mathrm{C} / \mathrm{N}$ 等指标重建了过去 500 年降水变化,并指出在年际一年代际时间尺 度上, 青海湖区域的水汽来源受到东亚季风的控制, 而非印度季风. 而且在过去 500 年内的年际、年代际时 间尺度上, 青海湖附近的西宁市旱涝指数与东亚季风控制区的华北旱涝指数变化一致 ${ }^{[34]}$, 这进一步说明了 东亚夏季风对该区降水具有重要的贡献. 来自于黄土高原上的 267 个古土壤发育年代数据的频率分布分析 结果显示, 8.6 3.2 ka 黄土高原古土壤普遍发育, 指示了这一时期黄土高原降水最多 ${ }^{[63]}$. 中国北方岱海沉积 记录 ${ }^{[64]}$ 、洛川榆林黄土剖面 ${ }^{[65]}$ 以及关中盆地黄土剖面基于环境磁学指标重建的夏季风降水历史 ${ }^{[6]}$ 均反映 出, 全新世东亚夏季风最强盛时段出现在距今约 $8 \mathrm{ka}$ 后的中全新世. 基于山西宁武公海沉积物狍粉资料重 建的全新世华北地区降水显示, 早全新世东亚夏季风持续增强, 7.8 5.3 ka 夏季风最强盛; $5 \mathrm{ka}$ 以来持续减 弱, 尤其是 $3 \mathrm{ka}$ 以来快速减弱 ${ }^{[67]}$. 这些地质记录一致表明, 东亚季风在中全新世达到鼎盛时期.

由此可见,全新世青海湖沉积物 TOC 的变化与区域降水变化并非完全一致:早全新世青海湖区域降水 较少而 TOC 含量整体较高, 但中晚全新世二者表现出较高的一致性. 因此, 将青海湖沉积物 TOC 解释为夏 季风强度或者季风降水的结论是值得商榷的. 青海湖 QH-2000 钻孔沉积物的 $\mathrm{C} / \mathrm{N}$ 比值大部分小于 $10^{[11]}$, 指示了青海湖沉积物有机质的供应主要来自湖泊自生水生植物 ${ }^{[68]}$; 另外 Liu 等 ${ }^{[21]}$ 对现代沉积物研究发现 水生植物类型显著影响了沉积物有机质碳同位素的组成, 因此可以推断, 青海湖水生植物是沉积物有机质 的主要来源, 全新世青海湖 TOC 的变化反映了湖泊自生生产力的变化. 另一方面, 湖泊沉积物 TOC 除了受 到湖泊的初始生产力和流域有机质输人的影响外, 也受到有机质保存能力的制约. 不可否认青海湖沉积物 


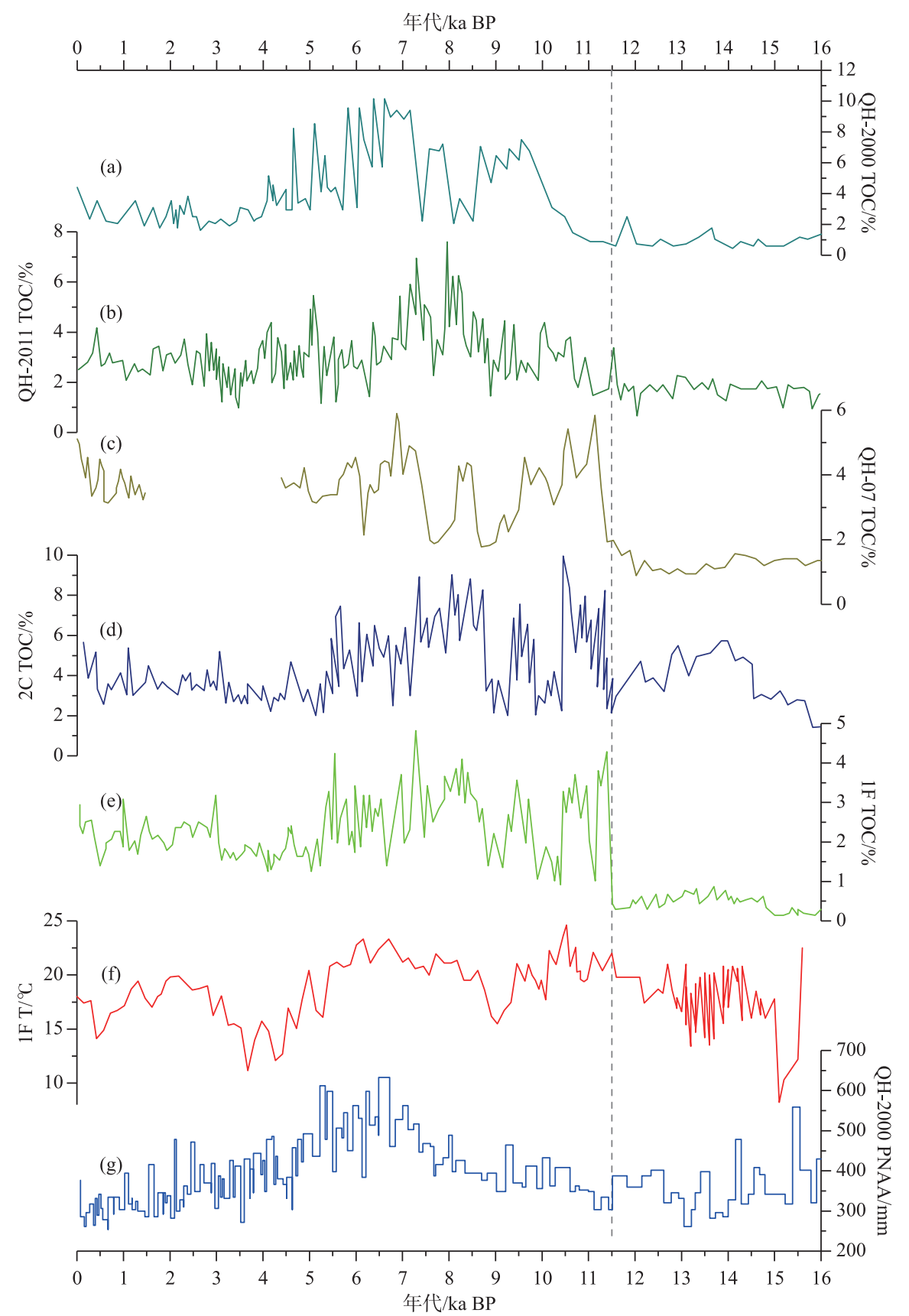

图 3 末次冰期一全新世青海湖沉积物 TOC 变化 $\left(\mathrm{a}^{[11]} 、 \mathrm{~b}^{[8]} 、 \mathrm{c}^{[5]} 、 \mathrm{~d}^{[38]} 、 \mathrm{e}^{[5]}\right)$ 与温度 $(\mathrm{f})^{[7]}$ 、降水 $(\mathrm{g})^{[30]}$ 的对比 (垂直虚线为末次冰期与全新世的分界线)

Fig.3 Variation of TOC $\left(\mathrm{a}^{[11}, \mathrm{b}^{[8]}, \mathrm{c}^{[5]}, \mathrm{d}^{[38]}, \mathrm{e}^{[5]}\right)$ during the last glacial to the Holocene recorded in Lake Qinghai and its relationship with temperature $(f)^{[7]}$ and precipitation $(g)^{[30]}$ (The vertical dashed line is the boundary between the last glacial and the Holocene) 
胶黄铁矿 ${ }^{[69]}$. 青海湖顶部大约 $5 \mathrm{~m}$ 的全新世沉积物由深灰色一浅棕色湖相粉砂质黏土或者具有水平层理的 黏土组成 ${ }^{[4]}$, 而且其磁化率表现为低值且没有像冰期那样的剧烈波动 ${ }^{\left[{ }^{[6]}\right]}$, 并与 $\mathrm{Fe}$ 含量的变化趋势一致 ${ }^{[6]}$, 这除了与有机质和碳酸盐等的稀释作用导致的沉积物中较低的磁性矿物浓度有关外, 也反映了全新世相对 稳定的沉积环境和有限的后期磁性矿物改造作用, 进而揭示了较低的有机质分解程度. 此外, 沉积物中 TOC 含量也受到沉积物颗粒大小以及沉积模式的影响 ${ }^{[70]}$, 因此在可靠年代控制下的有机质沉积通量变化往往更 能有效地反映 TOC 的变化 ${ }^{[68]}$. An 等 ${ }^{[4]}$ 计算的青海湖 TOC 的沉积通量变化与 TOC 含量变化具有一致的趋 势, 这说明稀释效应对全新世青海湖 TOC 的影响不大. 最新的一项基于青海湖生物标志化合物长链烯酮的 夏季温度重建结果显示 (图 3f), 早全新世温度波动较大 ${ }^{[7]}$, 这正好对应于 TOC 的显著波动. 同时就整个全 新世而言, TOC 的波动与重建温度的变化也具有较好的相关性. 因此温度也是控制青海湖 TOC 变化的重要 影响因素.

综上, 青海湖全新世沉积物 TOC 含量变化不是可靠的亚洲夏季风降水强度变化的指标, 而是降水、温 度、沉积来源及矿物稀释等众多因素的综合影响结果. 因此, 将湖泊沉积物 TOC 含量作为亚洲夏季风的代用 指标使用时需要特别谨慎.

\section{3 冰期一间冰期青海湖 TOC 变化及其指示意义}

在冰期一间冰期时间尺度上, 青海湖沉积物 TOC 表现出显著的差异. 末次冰期 TOC 为低值且波动较小. 因此基于 $\mathrm{TOC}$ 以及 $\mathrm{CaCO}_{3}$ 的变化, $\mathrm{Liu}$ 等 ${ }^{[6]}$ 认为青海湖区域末次冰期的气候是稳定的. 但是狍粉、元素地球 化学等资料却显示冰期气候不稳定, 也存在一系列千年时间尺度的气候突变事件 ${ }^{[11,18]}$. 同时, 青藏高原东北 缘的其他地质记录均揭示出晚冰期的 B-A 事件、YD 事件等表现显著 ${ }^{[30,71]}$. 位于青海湖东南方向的陇西黄土 高原的黄土记录也显示, 这一区域在末次冰期夏季风和降水存在显著的千年时间尺度的波动 ${ }^{[61-62,72]}$. 当然, 在冰期一间冰期尺度上, 间冰期夏季风强盛, 同时增加的温度和降水会导致流域生产量的增加, 进而湖泊陆 源有机质的输人量会伴随径流输人量的增大而增加; 同时相对暖湿的环境增加了湖泊营养物质的供应, 从 而也使得湖泊生产力有所增高, 因此陆源和水体生产力的增高会导致湖泊沉积物有机质含量的增大; 在冰 期则相反; 这种情形不论在季风区的湖泊还是我国受西风环流控制的内陆干旱区湖泊记录均是如此. 在季 风区湖泊中, 冰期一间冰期尺度上将 TOC 作为夏季风指标尽管不准确, 但指示的夏季风在轨道尺度的变化 不会有大的问题,例如利用青海湖 ${ }^{[4-6]}$ 或者云南鹤庆盆地 ${ }^{[3]}$ 湖泊沉积物 TOC 指标重建的间冰期夏季风强盛 和冰期夏季风微弱的变化模式, 但这并不能说明 TOC 可以作为亚洲夏季风的可靠指标, TOC 记录也仅可能 反映出冰期一间冰期尺度的大幅度季风变化而未能很好地刻画出冰期内部弱季风的波动.

\section{3 结论}

本文以青海湖研究为例, 讨论了不同时间尺度上其沉积物 TOC 的变化以及可能的控制因素. 结果显示, 过去千年青海湖不同位置钻孔的 TOC 和有机质表现出一致的变化趋势, 以百年尺度周期性旋回为主, 受到 降水与温度的共同影响. 通过对比区域基于狍粉的降水定量重建结果、湿度状况以及基于生物标志化合物 重建的夏季温度变化等, 发现全新世青海湖沉积物 TOC 的整体变化与区域降水不完全一致, 主要体现在早 全新世青海湖区域降水较少而 TOC 含量整体较高, 故将其解释为夏季风强度或者季风降水的结论需谨慎对 待. 在冰期环境青海湖 TOC 含量较低且波动较小, 没有记录到千年时间尺度气候事件. 冰期一间冰期时间尺 度上青海湖沉积物 TOC 的巨大差异突显了冰期和间冰期降水与温度的巨大变幅. 因此, 不同时间尺度下, 青 海湖湖泊沉积物 TOC 对气候变化的敏感性不同, 其沉积物 TOC 的变化是多个因素共同作用的综合表征, 不 能笼统而简单地将其作为季风降水强度的指标.

致谢: 感谢兰州大学张家武教授的宝贵意见!

\section{4 参考文献}

[ 1 ] Shen J, Zhang EL, Xia WL. Records from lake sediments of the Qinghai Lake to minor climatic and environmental changes of the past about 1000 years. Quaternary Science, 2001, 21(6): 508-513. [沈吉, 张恩楼, 夏威岗. 青海湖近千年来气 候环境变化的湖泊沉积记录. 第四纪研究, 2001, 21(6): 508-513.] 
[ 2 ] Zhang EL, Shen J, Wang SM et al. Climate and environment change during the past 900 years in Qinghai Lake. J Lake $S c i, 2002,14$ (1) : 32-38. DOI: 10.18307/2002.0105. [张恩楼, 沈吉, 王苏民等. 青海湖近 900 年来气候环境演化 的湖泊沉积记录. 湖泊科学, $2002, \mathbf{1 4}(1): 32-38$. ]

[ 3 ] An Z, Clemens SC, Shen J et al. Glacial-interglacial Indian summer monsoon dynamics. Science, 2011, 333 (6043): 719-723.

[ 4 ] An Z, Clemens SM, Zhou W et al. Interplay between the Westerlies and Asian monsoon recorded in Lake Qinghai sediments since 32 ka. Scientific Reports, 2012, 2 : 619. DOI: 10.1038/srep00619.

[ 5 ] Liu X, Colman SM, Brown ET et al. A climate threshold at the eastern edge of the Tibetan plateau. Geophysical Research Letters, 2014, 41(15) : 5598-5604.

[ 6 ] Liu X, Colman SM, Brown ET et al. Abrupt deglaciation on the northeastern Tibetan Plateau: evidence from Lake Qinghai. Journal of Paleolimnology, 2014, 51(2) : 223-240.

[ 7 ] Hou J, Huang Y, Zhao J et al. Large Holocene summer temperature oscillations and impact on the peopling of the northeastern Tibetan Plateau. Geophysical Research Letters, 43: 1323-1330.

[ 8 ] Yang J, Jiang H, Dong H et al. Sedimentary archaeal amoA gene abundance reflects historic nutrient level and salinity fluctuations in Qinghai Lake, Tibetan Plateau. Scientific Reports, 2015, 5: 18071. DOI: 10.1038/srep18071.

[ 9 ] Chen FH, Dong GH, Zhang DJ et al. Agriculture facilitated permanent human occupation of the Tibetan Plateau after 3600 BP. Science, 2015, 347(6219) : 248-250.

[10] Madsen DB, Ma H, Brantingham P et al. The late upper paleolithic occupation of the northern Tibetan Plateau margin. Journal of Archaeological Science, 2006, 33(10): 1433-1444.

[11] Shen J, Liu XQ, Wang SM et al. Palaeoclimatic changes in the Qinghai Lake area during the last 18,000 years. Quaternary International, 2005, 136(1): 131-140.

[12] Brantingham PJ, Gao X. Peopling of the northern Tibetan Plateau. World Archaeology, 2006, 38(3) : $387-414$.

[13] Rhode D, Zhang H, Madsen DB et al. Epipaleolithic/early Neolithic settlements at Qinghai Lake, western China. Journal of Archaeological Science, 2007, 34(4) : 600-612.

[14] Hou GL, Xu CJ, Fan QS. Three expansions of prehistoric humans towards northeast margin of Qinghai-Tibet Plateau and environmental change. Acta Geographica Sinica, 2010, 65(1): 65-72. [侯光良，许长军，樊启顺. 史前人类向青藏高 原东北缘的三次扩张与环境演变. 地理学报, 2010, 65(1): 65-72.]

[15] Chen F, Wu D, Chen J et al. Holocene moisture and East Asian summer monsoon evolution in the northeastern Tibetan Plateau recorded by Lake Qinghai and its environs: A review of conflicting proxies. Quaternary Science Reviews, 2016, 154: 111-129.

[16] Liu XQ, Shen J, Wang SM et al. Southwest monsoon changes indicated by oxygen isotope of ostracode shells from sediments in Lake Qinghai since the late Glacial. Chinese Science Bulletin, 2007, 52(4) : 539-544.

[17] Thomas EK, Huang Y, Clemens SC et al. Changes in dominant moisture sources and the consequences for hydroclimate on the northeastern Tibetan Plateau during the past 32 kyr. Quaternary Science Reviews, 2016, 131(Part A) : 157-167.

[18] Jin Z, An Z, Yu J et al. Lake Qinghai sediment geochemistry linked to hydroclimate variability since the last glacial. Quaternary Science Reviews, 2015, 122: 63-73.

[19] Fan Q, Ma H, Cao G et al. Geomorphic and chronometric evidence for high lake level history in Gahai Lake and Toson Lake of north-eastern Qaidam Basin, north-eastern Qinghai-Tibetan Plateau. Journal of Quaternary Science, 2012, 27( 8) : 819-827.

[20] Fan Q, Ma H, Wei H et al. Holocene lake-level changes of Hurleg Lake on northeastern Qinghai-Tibetan Plateau and possible forcing mechanism. Holocene, 2014, 24(3) : 274-283.

[21] Liu W, Li X, An Z et al. Total organic carbon isotopes: a novel proxy of lake level from Lake Qinghai in the Qinghai-Tibet Plateau, China. Chemical Geology, 2013, 347: 153-160.

[22] Wang H, Dong H, Zhang C et al. Water depth affecting thaumarchaeol production in Lake Qinghai, northeastern QinghaiTibetan plateau: Implications for paleo lake levels and paleoclimate. Chemical Geology, 2014, 368: 76-84.

[23] Liu X, Lai Z, Madsen DB et al. Last deglacial and Holocene lake level variations of Qinghai Lake. Journal of Quaternary Science, 2015, 30(3) : 245-257.

[24] Lu H, Zhao C, Mason J et al. Holocene climatic changes revealed by aeolian deposits from the Qinghai Lake area (north- 
eastern Qinghai-Tibetan Plateau) and possible forcing mechanisms. Holocene, 2010, 21(2) : 297-304.

[25] Lu R, Jia F, Gao S et al. Holocene aeolian activity and climatic change in Qinghai Lake basin, northeastern Qinghai-Tibetan Plateau. Palaeogeography, Palaeoclimatology, Palaeoecology, 2015, 430 : 1-10.

[26] Qiang M, Chen F, Song L et al. Late Quaternary aeolian activity in Gonghe Basin, northeastern Qinghai-Tibetan Plateau, China. Quaternary Research, 2013, 79(3) : 403-412.

[27] Yu LP, Lai ZP. OSL chronology and palaeoclimatic implications of aeolian sediments in the eastern Qaidam Basin of the northeastern Qinghai-Tibetan Plateau. Palaeogeography, Palaeoclimatology, Palaeoecology, 2012, 337/338: 120-129.

[28] Du NQ, Kong ZC, Shan FS. A preliminary investigation on the vegetational and climatic changes since 11000 years in Qinghai Lake-an analysis based on palynology in core QH85-14C. Acta Botanica Sinica, 1989, 31(10) : 803-814. [杜乃 秋, 孔昭宸, 山发寿. 青海湖 QH85-14C 钻孔孢粉分析及其古气候古环境的初步探讨. 植物学报, 1989, 31(10): 803-814. ]

[29] Cheng B, Chen F, Zhang J. Palaeovegetational and palaeoenvironmental changes since the last deglacial in Gonghe Basin, northeast Tibetan Plateau. Journal of Geographical Sciences, 2013, 23(1) : 136-146.

[30] Li J, Dodson J, Yan H et al. Quantitative precipitation estimates for the northeastern Qinghai-Tibetan Plateau over the last 18000 years. Journal of Geophysical Research Atmospheres, 2017, 122(10) : 5132-5143.

[31] Wang Y, Herzschuh U, Shumilovskikh LS et al. Quantitative reconstruction of precipitation changes on the NE Tibetan Plateau since the Last Glacial Maximum-extending the concept of pollen source area to pollen-based climate reconstructions from large lakes. Climate of the Past, 2014, 10(1) : 21-39.

[32] Ji J, Shen J, Balsam W et al. Asian monsoon oscillations in the northeastern Qinghai-Tibet Plateau since the late glacial as interpreted from visible reflectance of Qinghai Lake sediments. Earth Planet Science Letter, 2005, 233(1) : 61-70.

[33] Liu Z, Henderson ACG, Huang Y. Regional moisture source changes inferred from late Holocene stable isotope records. Advance in Atmospheric Sciences, 2008, 25(6) : 1021-1028.

[34] Xu H, Hou ZH, Ai L et al. Precipitation at Lake Qinghai, NE Qinghai-Tibet Plateau, and its relation to Asian summer monsoons on decadal/interdecadal scales during the past 500 years. Palaeogeography, Palaeoclimatology, Palaeoecology, $2007,254(3)$ : 541-549.

[35] Lister GS, Kelts KR, Chen KZ et al. Lake Qinghai, China: closed- basin lake levels and the oxygen isotope record for ostracoda since the latest Pleistocene. Palaeogeography, Palaeoclimatology, Palaeoecology, 1991, 84(1) : 141-162.

[36] Guo XL, Wang Q, Shi JA et al. Characteristics of the total organic carbon and organic carbon isotope and grain size and paleoclimate significance in Qinghai Lake sediments. Marine Geology and Quaternary Geology, 2002, 22(3) : 99-103. [郭雪莲, 王琪, 史基安等. 青海湖沉积物有机碳含量与同位素和粒度特征及其古气候意义. 海洋地质与第四纪地 质, 2002, 22(3): 99-103.]

[37] Wang Y, Shen J, Xu X et al. Environmental changes during the past 13500 cal. a BP deduced from lacustrine sediment records of Lake Qinghai, China. Chinese Journal of Geochemistry, 2011, 30(4) : 479-489.

[38] Zhou W, Liu T, Wang H et al. Geological record of meltwater events at Qinghai Lake, China from the past 40 ka. Quaternary Science Reviews, 2016, 149: 279-287.

[39] Zhang JW. High-resolution Holocene paleoenvironmental reconstruction through lake sediments and loess-paleosol sequences in monsoonal boundary area in central China[Dissertation]. Lanzhou: Lanzhou University, 2001. [张家武. 季 风边缘地区全新世高分辨率湖泊与黄土沉积记录研究 [学位论文]. 兰州: 兰州大学, 2001.]

[40] Zhang J, Jin M, Chen F et al. High-resolution precipitation variations in the northeast Tibetan Plateau over the last 800 years documented by sediment cores of Qinghai Lake. Chinese Science Bulletin, 2003, 48(14) : 1451-1456.

[41] Xu H, Ai L, Tan L et al. Geochronology of a surface core in the northern basin of Lake Qinghai : Evidence from ${ }^{210} \mathrm{~Pb}$ and ${ }^{137}$ Cs radionuclides. Chinese Journal of Geochemistry, 2006, 25(4) : 301-306.

[42] Xu H, Ai L, Tan L et al. Stable isotopes in bulk carbonates and organic matter in recent sediments of Lake Qinghai and their climatic implications. Chemical Geology, 2006, 235(3) : 262-275.

[43] Dean WE. Determination of carbonate and organic matter in calcareous sediments and sedimentary rocks by loss on ignition: comparison with other methods. Journal of Sedimentary Petrology, 1974, 44(1) : 242-248.

[44] Liu ZT, Yu JQ, Zhang BH et al. Application of loss on ignition to the study of lake sediments and environmental changes. Journal of Salt Lake Research, 2006, 14(2): 67-72. [刘子亭, 余俊清, 张保华等. 烧失量分析在湖泊沉积与环境变 
化研究中的应用. 盐湖研究, 2006, 14(2): 67-72.]

[45] Shen M, Piao S, Jeong SJ et al. Evaporative cooling over the Tibetan Plateau induced by vegetation growth. Proceedings of the National Academy of Sciences, 2015, 112(30): 9299-9304.

[46] Chen XG, Li JP, Li ZJ et al. Vegetation coverage and its relation with climate change in Qinghai Lake area. Journal of Desert Research, 2007, 27 (5):797-804. [陈晓光, 李剑萍, 李志军等. 青海湖地区植被覆盖及其与气温降水变化 的关系. 中国沙漠, 2007, 27 (5): 797-804.]

[47] Wang YJ, Zhou XL, Ni SX et al. Analysis on climate change in the region of Qinghai Lake in the last 40 years. Journal of Nanjing Institute of Meteorology, 2003, 26(2): 228-235. [王艳姣, 周晓兰, 倪绍祥等. 近 40a 来青海湖地区的气候 变化分析. 南京气象学院学报, 2003, 26(2): 228-235.]

[48] Ao H, Wu C, Xiong X et al. Water and sediment quality in Qinghai Lake, China: a revisit after half a century. Environmental Monitoring and Assessment, 2014, 186(4) : 2121-2133.

[49] Zhang H, Werner JP, García-Bustamante E et al. East Asian warm season temperature variations over the past two millennia. Scientific Reports, 2018, 8(1) : 7702. DOI: 10.1038/s41598-018-26038-8.

[50] Liu X, Yu Z, Dong H et al. A less or more dusty future in the Northern Qinghai-Tibetan Plateau. Scientific Reports, 2014, 4(6672): 1-6.

[51] Xu H, Liu X, Hou Z. Temperature variations at Lake Qinghai on decadal scales and the possible relation to solar activities. Journal of Atmospheric and Solar-Terrestrial Physics, 2008, 70(1) : 138-144.

[52] Zhao C, Liu Z, Rohling EJ et al. Holocene temperature fluctuations in the northern Tibetan Plateau. Quaternary Research, $2013, \mathbf{8 0}(1)$ : 55-65.

[53] Yang B, Qin C, Wang J et al. A 3500-year tree-ring record of annual precipitation on the northeastern Tibetan Plateau. Proceedings of the National Academy of Sciences, 2014, 111 ( 8) : 2903-2908.

[54] Leng MJ, Marshall JD. Paleoclimate interpretation of stable isotope data from lake sediment archives. Quaternary Science Reviews, 2004, 23(7) : 811-831.

[55] Liu W, Zhang P, Zhao C et al. Reevaluation of carbonate concentration and oxygen isotope records from Lake Qinghai, the northeastern Tibetan Plateau. Quaternary International, 2018, 482 : 122-130.

[56] Yang X, Liu J, Liang $\mathrm{F}$ et al. Holocene stalagmite $\delta^{18} \mathrm{O}$ records in the East Asian monsoon region and their correlation with those in the Indian monsoon region. Holocene, 2014, 24(12): 1657-1644.

[57] Liu J, Chen J, Zhang X et al. Holocene East Asian summer monsoon records in northern China and their inconsistency with Chinese stalagmite $\delta^{18} \mathrm{O}$ records. Earth-Science Review, 2015, 148: 194-208.

[58] Gou X, Deng Y, Chen F et al. Precipitation variations and possible forcing factors on the Northeastern Tibetan Plateau during the last millennium. Quaternary Research, 2014, 81(3) : 508-512.

[59] Yu J. Lake Qinghai, China: A multi-proxy investigation on sediment cores for the reconstructions of paleoclimate and paleoenvironment since the Marine Isotope Stage 3. Dissertation, Faculty of Materials and Geoscience, Technical University of Darmstadt, 2005.

[60] Stauch G, Lai Z, Lehmkuhl F et al. Environmental changes during the late Pleistocene and the Holocene in the Gonghe Basin, north-eastern Tibetan Plateau. Palaeogeography, Palaeoclimatology, Palaeoecology, 2018, 509: 144-155.

[61] Rao Z, Chen F, Cheng H et al. High-resolution summer precipitation variations in the western Chinese Loess Plateau during the last glacial. Scientific Reports, 2013, 3: 2785. DOI: 10.1038/srep02785.

[62] Chen FH, Bloemendal J, Wang JM et al. High-resolution multi-proxy climate records from Chinese loess: evidence for rapid climatic changes over the last 75 kyr. Palaeogeography, Palaeoclimatology, Palaeoecology, 1997, 130(1/2/3/4): 323-335.

[63] Wang H, Chen J, Zhang X et al. Palaeosol development in the Chinese Loess Plateau as an indicator of the strength of the East Asian summer monsoon: Evidence for a mid-Holocene maximum. Quaternary International, 2014, 334/335: 155-164.

[64] Xiao J, Xu Q, Nakamura T et al. Holocene vegetation variation in the Daihai Lake region of north-central China: a direct indication of the Asian monsoon climatic history. Quaternary Science Reviews, 2004, 23(14) : 1669-1679.

[65] Lu H, Yi S, Liu Z et al. Variation of East Asian monsoon precipitation during the past 21 k.y. and potential $\mathrm{CO}_{2}$ forcing. Geology, 2013, 41(9) : 1023-1026. 
[66] Xia D, Jia J, Li G et al. Out-of-phase evolution between summer and winter East Asian monsoons during the Holocene as recorded by Chinese loess deposits. Quaternary Research, 2014, 81(3) : 500-507.

[67] Chen F, Xu Q, Chen J et al. East Asian summer monsoon precipitation variability since the last deglaciation. Scientific Reports, 2015, 5: 11186. DOI: 10.1038/srep11186.

[68] Meyers PA, Lallier-Vergès E. Lacustrine sedimentary organic matter records of Late Quaternary paleoclimates. Journal of Paleolimnology, 1999, 21(3) : 345-372.

[69] Ai L, Qiang XK, Song YG et al. Identification of greigite in the late Pleistocene sediments of Lake Qinghai and its environmental implications. Chinese Journal of Geophysics, 2011, 54(9): 2309-2316. [艾莉, 强小科, 宋友桂等. 青海湖晚更 新世沉积物中胶黄铁矿的发现及其环境指示意义. 地球物理学报, 2011, 54(9): 2309-2316.]

[70] Meyers PA. Organic geochemical proxies of paleoceanographic, paleolimnologic, and paleoclimatic processes. Organic Geochemistry, 1997, 27(5/6): 213-250.

[71] Liu X, Dong H, Rech JA et al. Evolution of Chaka Salt Lake in NW China in response to climatic change during the Latest Pleistocene-Holocene. Quaternary Science Reviews, 2008, 27(7) : 867-879.

[72] Fang X, Pan B, Guan D et al. A 60000-year loess-paleosol record of millennial-scale summer monsoon instability from Lanzhou, China. Chinese Science Bulletin, 1999, 44(24) : 2264-2267. 